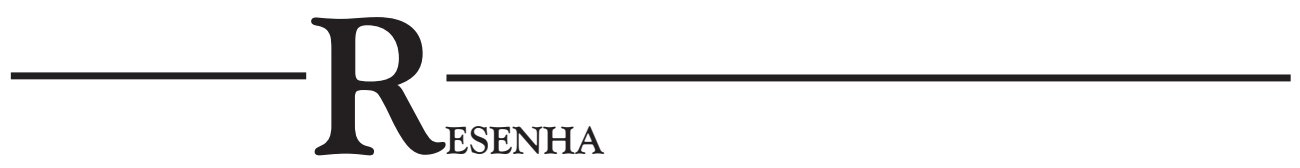

NOGUEIRA, Sidnei. Intolerância religiosa. São Paulo: Pólen, 2020, 160pp. (Coleção Feminismos Plurais).

Patrício Carneiro Araújo

Universidade da Integração Internacional da Lusofonia Afro-Brasileira

Redenção - CE - Brasil Orcid: https://orcid.org/0000-0001-5901-945X

\title{
A DENÚNCIA NEGRA DA VERDADE BRANCA SOBRE A INTOLERÂNCIA RELIGIOSA NO BRASIL
}

O livro Intolerância religiosa, do professor e doutor em Semiótica e Linguística Geral Sidnei Nogueira, é o oitavo volume da coleção Feminismos Plurais, coordenada pela filósofa negra brasileira Djamila Ribeiro. Tendo sido precedido na coleção por importantes nomes da intelectualidade negra brasileira contemporânea, como Djamila Ribeiro, Joice Berth, Juliana Borges, Carla Akotirene, Adilson Moreira, Silvio Almeida e Rodney William, o livro de Nogueira foi aguardado por muitos leitores.

A espera ansiosa, que seria interrompida em maio de 2020 - em plena pandemia de COVID-19 -, estava ligada tanto à importância do nome do autor quanto ao tema que seria abordado: intolerância religiosa. $\mathrm{E}$ a ansiedade não era injustificada. De fato, o livro de Sidnei representaria, por muitos motivos, uma significativa con- 
tribuição na discussão a ser feita. Contudo, antes de entrarmos nos méritos dessa contribuição, vejamos como está organizada a obra.

Precedido por uma apresentação feita por Djamila Ribeiro e sucedido por uma sequência de notas e referências bibliográficas, o livro está estruturado em quatro grandes seções: uma "Introdução" (:21-32) e três grandes capítulos intitulados, respectivamente, "Caminhos da história da intolerância religiosa" (:33-80), "A verdade sobre a intolerância religiosa é branca: mais um dos tentáculos do racismo" (:81-116) e "Da perseguição à cura: epistemologia negra como possibilidade de desconstrução do racismo religioso" (:117-136).

Grosso modo, a tese geral do livro consiste em explicar que as violências sofridas pelas populações de Comunidades Tradicionais de Terreiro (CTTro) - geralmente classificadas como "intolerância religiosa" -, na verdade, consistem em manifestações do racismo brasileiro. Essa tese está detalhadamente explicada ao longo do texto que também traz, principalmente no último capítulo, caminhos para a superação dessas violências às quais o autor termina por chamar de "racismo religioso". Ao assumir essa expressão, Sidnei acompanha e endossa uma tendência semântica muito forte nos círculos de pesquisas e militâncias sobre essa questão no Brasil, entre os anos 2019 e 2020. Vejamos como isso aparece em cada parte do livro.

$\mathrm{Na}$ "Introdução" (:21-32), o autor começa situando o visível antagonismo entre os dispositivos constitucionais da liberdade de crença e consciência, assegurados pela Constituição Federal de 1988, e as agressões sofridas pelas CTTro. Para isso, ele retoma um forte símbolo desse descompasso: o livro Orixás, caboclos e guias: deuses ou demônios?, de Edir Macedo. Segundo Sidnei, ao dedicar, ironicamente, esse livro aos sacerdotes de CTTro, Macedo contribui com o recrudescimento da violência contra as religiões afro no Brasil. O discurso de Macedo, porém, teria encontrado terreno fértil entre setores da população brasileira, possibilitando uma sistematização dos discursos demonizantes sobre essas religiões e o avanço de uma cultura cristã que gradativamente se imiscuiu na política institucional. Uma prova material disso seriam as placas colocadas na entrada de cidades brasileiras com dizeres evocativos da posse dessas cidades por parte de Jesus. Nogueira conclui a introdução indagando a serviço de quem estaria essa promiscuidade entre fé (evangélica), política, Estado e proselitismo.

No capítulo "Caminhos da história da intolerância religiosa" (:33-80), Sidnei refaz o percurso histórico do fenômeno da intolerância religiosa no Brasil e no mundo. Para tal, ele recorre a dados recentes coletados pela Fundação Pontifícia Aid to the Church in Need (ACN) em 196 países sobre violações significativas da liberdade religiosa. Para o Brasil, o autor retoma pesquisas realizadas em escolas públicas de São Paulo junto a professores e estudantes pertencentes a diferentes religiões. As conclusões revelam que, tanto no Brasil quanto no mundo, as violações têm aumentado. No caso do Brasil, as principais vítimas são as religiões afro-brasileiras. Nesse mesmo capítulo, ele ainda afirma que a expressão "intolerância religiosa" não dá conta de explicar as violências sofridas pelas populações de CTTro. Nesse caso, o véu da 
intolerância encobriria o racismo que motiva essas violências. Sugere, então, que se trata de racismo epistêmico, já que tal violência incide diretamente sobre os saberes africanos e afro-brasileiros cujos guardiões são os terreiros e suas lideranças.

As ideias lançadas no capítulo anterior são mais bem desenvolvidas no "A verdade sobre a intolerância religiosa é branca: mais um dos tentáculos do racismo" (:81-116). Aqui, Sidnei denuncia que, por trás da intolerância religiosa, há uma branquitude racista em atuação. Ele assume, então, a expressão "Racismo Religioso" como substitutivo de intolerância religiosa. A base para essa mudança são as falas dos seus entrevistados, cujo perfil aponta para o religioso militante. Mesmo não implicando uma ruptura total com a ideia de intolerância, a mudança de linguagem parece possuir uma importante eficácia heurística para explicar as interseções entre violência religiosa e racismo. Segundo Sidnei, a violência atinge diretamente as práticas afro-religiosas e está ligada à ignorância sobre elas, motivo pelo qual ele passa a explicar os sentidos de algumas dessas práticas e saberes ancestrais, como a sacralização do abate animal nas CTTro e o consumo da carne resultante dele. Entre os ritos explicados, estão o A se orò n’pá (imolação), Sasányìn (canto das folhas), İyanlé (oferenda de comidas), İpadé (saudação a Ėšù) e Léhìn (refeição comunal).

Depois de explicar as violências sofridas pelo povo de CTTro, identificando-as com o racismo religioso, Sidnei apresenta caminhos e estratégias para a sua superação no capítulo "Da perseguição à cura: epistemologia negra como possibilidade de desconstrução do racismo religioso" (:117-136). Ainda em tom de denúncia, ele afirma que "O racismo religioso quer matar existência, eliminar crenças, apagar memórias, silenciar origens" (:123). Para evitar que isso aconteça, segundo o autor, há que se expandir os cosmossentidos afrodiaspóricos e a alteridade, além de promover a ética do candomblé como cura. Isso se traduz em revisão de práticas, linguagens e condutas, tanto por parte da sociedade mais abrangente quanto por parte dos religiosos e lideranças de CTTro. As epistemologias negras precisariam ser assumidas definitivamente como ferramentas de desconstrução do racismo religioso. Não se trataria, portanto, de uma questão meramente religiosa, e sim epistêmica.

O livro de Sidnei Nogueira situa-se em um lugar de fala específico ao discutir o que discute. Negro e babalorixá da Comunidade da Compreensão e da Restauração Ilé Àsé Sàngó (CCRIAS), na cidade de Suzano, São Paulo, ele fala do que vive. Logo, trata-se de um típico intelectual orgânico ou pesquisador insider. Ter sido convidado para escrever este volume da coleção Feminismos Plurais já revela em que círculos ele transita e em que relações está envolvido. Ao ser apresentado por Kiusam de Oliveira e Oswaldo Faustino, nas "orelhas" do livro, Sidnei é reconhecido como importante voz negra no cenário atual.

Como babalorixá e cientista social, ele tem se empenhado na revisão de práticas afrorreligiosas e na proposição de uma linguagem decolonial que rompa com os resquícios do racismo secular que condicionou essas religiões na diáspora. Sua obra, 
portanto, representa uma importante contribuição para os estudos sobre a herança cultural-civilizacional africana na diáspora, além de ser instrumento eficaz no combate ao racismo, seja ele religioso, epistêmico, cultural, seja de qualquer outra natureza.

O livro mostra-se em consonância com um processo de mudança no foco dos estudos sobre intolerância religiosa no Brasil, ao dar maior visibilidade à realidade das religiões afro-brasileiras. Sinal de que as pesquisas têm conseguido captar a realidade da vida social, ao demonstrarem que essas são as expressões religiosas que mais têm sido alvo de ataques atualmente. Nesse sentido, trata-se também de uma mudança de agência e protagonismo endógeno às populações negras e afrorreligiosas brasileiras. Isso revela o quanto o campo religioso tem se transformado e que populações silenciadas por serem tidas como minorias numéricas agora conseguem publicar suas investigações e demonstrar que foram relegadas à condição de minorias sociológicas por causa do seu pertencimento étnico-racial.

Sidnei, contudo, não rompe totalmente com a linguagem utilizada até então para se pensar as múltiplas violências contra a população negra e afrorreligiosa no Brasil. O próprio título do livro confirma isso: "Intolerância Religiosa", e não "Racismo Religioso", como a própria coleção vem fazendo, ao falar de "racismo recreativo", "racismo estrutural", etc. Aliás, uma simples estatística da obra revela a manutenção do campo semântico já existente. Sidnei refere-se 29 vezes à "intolerância religiosa" e apenas 11 vezes a "racismo religioso". Seguem-se 43 vezes a "racismo" e 1 vez a "racismo científico", "epistêmico" e "cultural". Não obstante, para 43 referências a "racismo", temos 25 à "intolerância". Sendo assim, se não há ruptura total na linguagem, ao menos há forte proposição de uma ruptura epistemológica.

Submetido em: $14 / 06 / 2020$

Aceito em: 08/07/2020

\section{Patrício Carneiro Araújo* (patricionisoji@unilab.edu.br)}

* Professor Adjunto de Antropologia na Universidade da Integração Internacional da Lusofonia Afro-Brasileira (UNILAB), Redenção, CE, Brasil; Líder do Tierno Bokar: Núcleo de estudos e pesquisa sobre o fenômeno religioso (UNILAB/CNPq); Doutor em Ciências Sociais (Antropologia) pela Pontifícia Universidade Católica de São Paulo (PUC-SP), São Paulo, SP, Brasil. 